\title{
Notas sobre a experiência qualitativa em Dewey
}

Leoni Maria Padilha Henning

Universidade Estadual de Londrina

\section{Resumo}

Este artigo analisa a "experiência" deweyana considerando a estética, pois experienciar no âmbito das relações humanas é mais do que a simples atividade do corpo desvinculado do espírito, não ocorrendo também apenas na dimensão intelectual. $\mathrm{O}$ autor defende a continuidade da experiência estética a toda experiência humana, como também analisa as questões relativas à arte. Neste trabalho, tentamos explorar especialmente o primeiro caso. Ao aproximar ciência, arte, filosofia e educação, Dewey exemplifica uma das suas preocupações, os dualismos, perniciosos à experiência integrada - educativa em seu percurso para a consecução e consumação, mas não meramente para a chegada a um fim ou cessação.

Palavras-chave: experiência; filosofia da educação; filosofia estética.

\begin{abstract}
This paper examines deweyan "experience" in terms of esthetics, as experience in the context of human relationships is more than the simple activity of a body unbound from the spirit, not just occurring also in the intellectual dimension. The author defends the continuity of aesthetic experience to all human experience, but also analyzes the issues relating to art itself. In this paper, we try to exploit in particular the first case. By bringing science, art, philosophy and education, Dewey exemplifies one of his concerns, the dualisms which damages the integrated experience - really educative - on its way for the achievement and fulfillment, but not merely for the coming to an end or termination.
\end{abstract}

Keywords: experience; philosophy of education; aesthetic philosophy.

Filosofia e Educação [rfe] - volume 7, número 2 - Campinas, SP Junho-Setembro de 2015 - ISSN 1984-9605 - p. 47-74 


\section{Introdução}

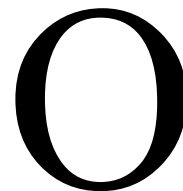

conceito de experiência em Dewey se comporta como princípio subjacente à estrutura do pensamento filosófico-educacional do autor, de forma que o encontramos pormenorizadamente explicitado e amplamente utilizado nas reflexões que o autor realiza nos mais diversos âmbitos com os quais se ocupa em sua análise. Nesse sentido, trata-se mesmo de um conceito fundamental se quisermos de fato entender o filósofo norte-americano, suas propostas e análises apresentadas em suas principais obras, dentre as quais ressaltamos primeiramente Experience and Nature (1926), da qual temos traduzido para o português, apenas dois capítulos (I e V) na $1^{\mathrm{a}}$. edição da coleção Os Pensadores (1974), em seu volume XL.

O referido livro foi publicado em 1925 pela iniciativa da família do alemão Paul Carus (1852-1919), doutor em filosofia em 1876 pela Universidade de Strassburg e um entusiasta pelo campo intelectual entendido por ele como fundamento que deveria ser cultivado em vista do futuro da cultura humana. Tal empreendimento editorial foi intitulado "Paul Carus Lectures" que se concretizou em "[...] uma série de volumes [....] representativos das fases mais refinadas do pensamento especulativo" (ALEXANDER, 1926, p. xi, tradução nossa), e foi iniciada exatamente com John Dewey, cuja justificativa foi assim expressa: “[...] pois não existe um filósofo Americano vivo sobre o qual se pode falar mais verdadeiramente que a sua influência é a do tipo que representa o ideal de Dr. Carus" (ALEXANDER, 1926, p. xi, tradução nossa).

Dewey, então, inicia Experience and Nature (1926) problematizando o entendimento corrente e contraditório, em sua opinião, sobre "experiência", mostrando o quão dificultosa se torna a não clarificação filosófica do conceito. $\mathrm{O}$ autor se propõe a esclarecer o ponto crucial em

Filosofia e Educação [rfe] - volume 7, número 2 - Campinas, SP Junho-Setembro de 2015 - ISSN 1984-9605 - p. 47-74 
vista desse entendimento, ocupando-se, pois, da "experiência primária", cujo acesso poderia ser efetuado de um lado, a partir da experiência ordinária e cotidiana ou, de outro, a partir dos seus produtos refinados e constituídos pela experiência científica num retorno à experiência fundamental original. No entanto, adverte, "Cada caminho de abordagem tem suas vantagens e seus perigos" (DEWEY, 1926, p. 03, tradução nossa) justamente pelas dificuldades que cada uma das alternativas implica.

Um outro livro importante, que nos ajuda a compreender o tema aqui apresentado, foi tomado pelo próprio autor como o seu melhor trabalho (TEIXEIRA, 1952, p. 11). Trata-se de Democracia e Educação (1952), originalmente publicado em 1916, traduzido para o português por Godofredo Rangel e Anísio Teixeira somente em 1930. Tendo como subtítulo "Uma introdução à Filosofia da Educação" apresenta um conjunto de capítulos concernentes aos temas mais importantes, segundo o autor, a serem tratados na disciplina, dentre os quais encontramos o capítulo "Experiência e Pensamento".

Essa conexão entre experiência e pensamento nos leva a um outro trabalho de Dewey, publicado em 1933, que explicita a elaboração do pensamento, alcançando o pensamento reflexivo e reforçando a sua relação com os processos educativos. Trata-se de Como pensamos (1959), traduzido ao português por Haydée de Camargo Campos e publicado entre nós, em língua portuguesa, no mesmo ano. Esse fato demonstra a importância que o autor veio conquistando, como referência, no avanço das décadas da primeira metade do século XX, tendo isso sido grandemente reforçado pelo acirramento dos ânimos em torno das propostas dos Pioneiros da Escola Nova.

Por fim, Arte como Experiência de 1934, traduzido recentemente para o português (2010), nos traz novamente a perspectiva original da visão de

Filosofia e Educação [rfe] - volume 7, número 2 - Campinas, SP Junho-Setembro de 2015 - ISSN 1984-9605 - p. 47-74 
Dewey sobre a experiência, uma vez que é através da experiência estética que compreendemos a unicidade da experiência humana, apenas fracionada pela forma como entendemos o trabalho e pelo pensamento distanciado do mundo real. Para o autor, o exercício do experienciar no âmbito das relações humanas é mais do que a simples atividade do corpo desvinculado do espírito, não ocorrendo também apenas na dimensão intelectual. Defendendo a continuidade da experiência estética a toda experiência humana e analisando a arte como experiência, o autor percebe que as divisões que fazemos das diferentes modalidades do experienciar resultam dos dualismos cultivados em nossa cultura, sobre cuja problemática discutiremos oportunamente neste artigo. $\mathrm{Na}$ presente proposta daremos uma ênfase maior ao primeiro caso aludido acima, procurando analisar e compreender a experiência estética vinculada a toda sorte de experiência humana, uma vez que o segundo enfoque da questão, a arte como experiência, foi apenas parcialmente considerado, por requerer desta autora um maior aprofundamento, impossível para o momento. Contudo acreditamos, que o uso desta contribuição de Dewey, exequível para esta oportunidade, serviu-nos de importante aporte, mas, até aqui suficiente para atingirmos os propósitos estabelecidos neste estudo.

Assim, com este conjunto básico de trabalhos do autor, tentarei dar conta do tema proposto, agregando à discussão, eventualmente, alguns conteúdos de outros textos.

\section{Teoria da experiência deweyana}

Inicialmente observamos que o autor amplia o conceito de experiência de tal maneira que acaba por construir uma teoria sobre a qual advoga em sua obra como aquela que formulará uma outra visão explicativa da realidade, superando os dualismos. Nesse sentido, defrontando-se, ao longo das suas

Filosofia e Educação [rfe] - volume 7, número 2 - Campinas, SP Junho-Setembro de 2015 - ISSN 1984-9605 - p. 47-74 
reflexões, com uma seqüência de questionamentos diante dos quais se ocupa acirradamente, faz resultar desse trabalho um conjunto de escritos que o fizeram famoso como filósofo e educador de um perfil marcante. Pergunta-se o autor:

Por que a tentativa de ligar as coisas superiores e ideais da experiência às raízes vitais básicas é vista, com tanta frequência, como uma traição à sua natureza e uma negação de seu valor? Por que existe repulsa quando as realizações superiores da arte refinada são postas em contato com a vida comum, a vida que compartilhamos com todos os seres vivos? Por que se pensa na vida como uma questão de apetites inferiores ou, na melhor das hipóteses, uma coisa de sensações grosseiras, pronta a despencar do que tem de melhor para o nível da lascívia e da crueldade bruta? Uma resposta completa a essas perguntas envolveria a redação de uma história da moral que expusesse as condições que acarretaram o desprezo pelo corpo, o medo das sensações e a oposição da carne ao espírito (DEWEY, 2010, p. 85, grifos nossos).

Como podemos observar e reforçar nossa posição já anunciada anteriormente, o ponto de partida para melhor compreendermos o filósofo norte-americano é, de fato, partirmos do entendimento do que seja "experiência", cuja teoria resultante tornou-se eixo de sua construção intelectual, quer seja na filosofia, na arte, na psicologia ou na educação. Para ele, experiência simplesmente é vida, pois, como diz, “[...] ocorre continuamente, porque a interação do ser vivo com as condições ambientais está envolvida no próprio processo de viver" (DEWEY, 2010, p. 109). No entanto, os homens, principalmente aqueles que lidam com os objetos refinados da arte, da filosofia ou da ciência, têm dificuldade de recuperar 
esse universo da sua experiência primária para, de fato, elaborarem o "sentido" e a "significação" daquilo que experienciam.

Para iniciarmos a traçar um primeiro esboço do conceito, devemos partir da cosmologia esboçada por Dewey, em que então encontramos o cosmos constituído por uma variedade de corpos, organismos e elementos que, na "natureza", praticam a dinamicidade das mudanças e reciprocidades manifestas na "vida" por uma intensa, caótica, imprevisível interação, responsável por essa mobilidade permanente no mundo e pelas transformações constantes. Essas inúmeras, múltiplas e variadas relações se dão, primeiramente, a nível físico, quando alguns desses elementos ao interagirem provocam mudanças uns aos outros, mas de modo aleatório, sem qualquer esforço adaptativo ou autoconservativo. Trata-se de experiências puramente físicas.

Com respeito ao universo da vida, as reações de um corpo diante da ação de outro corpo revelam que o primeiro manifesta um esforço, embora às vezes mínimo, de conservação do seu caráter enquanto organismo ou indivíduo, buscando sempre adaptar-se. Trata-se aí das experiências puramente biológicas de seleção e adaptação - psicofísicas - adstritas ao mundo vegetal e animal.

Ocorre que, no universo da vida os momentos presentes na interação entre os corpos são basicamente: 1) o agir ou a atividade; 2) o sofrer a ação; e, 3) a devolução ou retorno, pela reação daquele que sofreu a primeira ação - e assim, sucessiva, ampla e aleatoriamente. Contudo, no plano do humano essa experiência, de algum modo e com um grau considerável e gradativo de aprimoramento, permite o controle do processo ao agente, chegando este a formas sofisticadas da experiência para além do biológico. Assim se dá a reflexão, a previsão dos resultados da ação pelo alcance das suas consequências, a elaboração de um conhecimento mais bem construído 
sobre o mundo, disso resultante, possibilitando isso tudo a reconstrução da sua experiência original própria aos patamares mais simples e situados nos planos anteriores. Desse modo, no universo humano também encontramos os níveis mais elementares de experiências às quais se somam aquelas inerentes aos seres inteligentes, reflexivos, experimentais, capazes de criar a cultura, as relações comunicativas pela linguagem, a preservação e a reconstrução da própria experiência pela educação. Ademais, é imprescindível observarmos que a vida não se constitui em uma marcha uniforme de momentos ininterruptos. Logo, a experiência vital é, na verdade, constituída por situações e episódios reais que 'podem ser' apreendidos na sua integralidade ou não.

Nesse caso, entendemos o porquê de Dewey associar vida, natureza, experiência e educação, termos que, embora bem definidos pelo autor, se inter-relacionam, se integram e se completam.

Nessa cosmologia deweyana encontramos desse modo, um patamar de experiência primária, original, fundamental, comum a todos, enquanto organismos vivos e seres de experiência bruta vivida no universo físico, biológico e natural, integrada com a natureza, sendo portanto "vida", "experiência" e, como num cenário ainda mais englobante, é "natureza". Diante dessa sua própria posição, Dewey caracterizou-a por "naturalismo empírico", "empirismo naturalista", "humanismo naturalista" e mais, “metafísica naturalista” (DEWEY, 1974, p. 161; SANTAYANNA, 1951, p. 245) - cujos qualificativos provocam intensas discussões merecedoras de outra oportunidade para o seu aprofundamento e uma rápida abordagem poderia prejudicar os propósitos da presente exposição. Contudo, o que podemos assinalar nesse particular é que, ao adotar tal posicionamento, uma explicação possível poderia ser colocada nesses termos: "Para o 'empiricista naturalista', essa elevação de nível [diante da constatação do aparecimento

Filosofia e Educação [rfe] - volume 7, número 2 - Campinas, SP Junho-Setembro de 2015 - ISSN 1984-9605 - p. 47-74 
da inteligência e suas consequências] não abre nenhum abismo intransponível entre a realidade e o conhecimento, o homem e a natureza, o espírito e matéria" (TEIXEIRA, 1965, p. 15, acréscimos nossos) uma vez que a experiência revela modos de existir da natureza, pois que envolve, pelo menos, dois elementos existentes no mundo, os quais ao se relacionarem, modificam-se mutuamente. Nesse sentido, considerando o entendimento do seu mais notável discípulo brasileiro, Anísio Teixeira (1900-1971), podemos afirmar que: "Experiência é uma fase da natureza, é uma forma de interação, pela qual os dois elementos que nela entram situação e agente - são modificados [...] um modo de existência da natureza [...] [que] é tão real quanto tudo que é real” (TEIXEIRA, 1965, p. 14, acréscimos nossos). Isso porque na interação estabelecida entre agente e situação, toda a realidade em questão é significativamente alterada - o que jamais se dá de modo definitivo. Trata-se da experiência existencial primária realizada na fragilidade do mundo em que vivemos cuja sua natureza é precária e incerta.

$\mathrm{O}$ apontamento sobre as referidas interações vivas, reais, ocorridas no processo contínuo de mudança em meio à natureza existencial refere-se ao sentido amplo de experiência, que muito se complexifica quando consideramos que tais alterações, quando ocorridas no âmbito humano, produzem o conhecimento e a reflexão. Nesses casos, observamos que essas alterações atingem tanto o agente cognoscente ou reflexivo quanto o objeto a que ele se dirige, uma vez que as relações entre ambos modificam-se e, em consequência disso, todo o ambiente no qual esse evento ocorre também sofre transformações e, assim se dá numa cadeia sucessiva.

Por ser a experiência primeiramente uma ocorrência orgânica do mundo, mas instável e indefinida, ela se constitui em fenômeno próprio à natureza e à vida, não apresentando, portanto, qualquer traço cognitivo 
necessário nesse limiar de experiência existencial (esta se nos ocorre, simplesmente!), resultando, na verdade, em readaptação de duas existências em atividade e em reação mútua. As modificações disso resultantes não são, no caso, percebidas; não são necessariamente levadas à consciência. Mas, quando isso acontece, a experiência produz grandes vantagens e benefícios ao homem, pois possibilita o controle das suas ações futuras tomando por base um método apropriado de aprendizagem que envolve a percepção, a análise, a investigação, o conhecimento e a experiência em processo contínuo. Então, referimo-nos à experiência como tentativa de elaborar um experimento, uma experimentação. Nesta etapa, aludimos ao aspecto "ativo" da experiência numa fase, digamos, "de aprimoramento", isto é, fazemos alguma coisa "intencionalmente" com algo que experienciamos ou desejamos experienciar. O aspecto "passivo" da experiência refere-se ao fato de termos experienciado a ação de algo sobre nós, à recepção de uma ação causadora da experiência enquanto reação do respondente que, ao mesmo tempo, é pois, efeito do mesmo processo. Mas, para ser fiel à sua integridade a real experiência deve, no seu conjunto, incluir necessariamente a ação - a recepção - a reação numa cadeia de abalos, cujo resultado sempre provoca consequências sobre nós e sobre o ambiente no qual estamos em atividade - processo que pode ser controlado numa fase mais adiantada do experienciar.

A experiência envolve, pois, um acontecimento com característica ativo-passiva. Em outras palavras, a combinação, a conexão desses dois aspectos é o que a evidencia fundamentalmente como tal, como uma experiência efetiva, constituindo-se cada um deles em aspectos próprios e necessários de uma real experiência. Isso é o que permite o reconhecimento da sua diferença em relação a uma mera atividade, a uma prática ou aos impulsos cegos. Estes revelam efemeridade, irreflexão, desvio de foco, 
dissipação (atributos impróprios de uma experiência efetiva). Assim, para haver uma real experiência é preciso a apreensão das conseqüências da ação impetradas por um agente sobre outro ou sobre algo ou sobre o seu ambiente, tratando-se de algo que se acumula, que é significativo, que é capaz de previsão, permitindo ainda o aumento de domínio do sujeito sobre o seu meio. Podemos desse modo dizer que "Aprendemos alguma coisa" (DEWEY, 1952, p. 192). Assim, o autor explica:

“Aprender da experiência” é fazer uma associação retrospectiva e prospectiva entre aquilo que fazemos às coisas e aquilo que em conseqüência essas coisas nos fazem gozar ou sofrer. Em tais condições a acção torna-se uma tentativa; experimenta-se o mundo para se saber como ele é; o que se sofrer em conseqüência torna-se instrução - isto é, a descoberta das relações entre as coisas (DEWEY, 1952, p. 193).

A experiência não se caracteriza, portanto, como trabalho essencialmente subjetivo e racional, podendo esse qualificativo ser incluído quando efetivamente ela se torna cumulativa e capaz de oferecer significados ao agente do conhecimento. Mas, tanto o espírito quanto o corpo participam efetivamente da experiência. Ampliando ainda mais essa compreensão, Dewey nos explica:

Toda vez que se rompe o elo que liga a criatura viva a seu meio ambiente, não há nada que una os diversos fatores e fases do eu. Pensamento, emoção, sentido, propósito e impulso se desagregam, sendo atribuídos a diferentes compartimentos do nosso ser. É que a unidade deles se encontra nos papéis cooperativos que todos 
desempenham nas relações ativas e receptivas com o meio (DEWEY, 2010, p. 439, grifos nossos)

A perspectiva estética é aquela que conclama todos esses fatores a fazerem parte real da experiência humana autêntica, estando cada um deles comprometido com a sua unidade, com o significado que dela puder ser extraído na sequência das ações prospectivas do seu agente.

Contudo, a experiência humana pode manifestar-se de diferentes formas como, por exemplo, a experiência banal, comum, aquela que pode ainda ser cultivada unicamente pelos procedimentos de tentativa e erro. Porém, quando não se apresenta apenas de forma caprichosa e rotineira, quando não se pauta em "experiências" isoladas ou de coisas arbitrariamente justapostas, pode agregar uma "nova qualidade" ao envolver a reflexão, o pensamento, aumentando o seu valor. Pois, desse modo, essa experiência revela-se sensível às relações entre uma ação e as suas consequências. Chamamo-la então de "experiência reflexiva", pois houve nesse caso, o cultivo deliberado do componente intelectual que não é excludente dos demais aspectos da vida humana.

Podemos então definir o "pensar", o elaborar juízos, segundo Dewey como:

[...] esforço intencional para descobrir as relações específicas entre uma coisa que fazemos e a consequência que resulta, de modo a haver continuidade entre ambas [...]; e toma seu lugar uma situação unificada a desenvolver-se. Compreende-se agora a ocorrência; esta ficou explicada; e achamos razoável, como costumamos dizer, que as coisas aconteçam de tal modo.

Pensar equivale, assim, patentear, a tornar explícito o elemento inteligível de nossa experiência. Tornar possível o proceder-se tendo 
um fim em vista. É a condição para podermos ter objectivos. (DEWEY, 1952, p. 200, itálicos do autor, grifos nossos).

Desse modo, quando surge o gérmen dessa nova qualidade, com o surgimento do elemento intelectual na experiência, podemos dizer que, se deliberada, a reflexão poderá ser acentuada. Ou seja, “[..] Pois [o indivíduo] toma uma coisa como prova de uma outra, reconhecendo, assim, uma relação entre ambas" (DEWEY, 1952, p. 201, acréscimos nossos). E, mais, "Qualquer futuro desenvolvimento, por mais apurado que seja, será apenas um prolongamento e um aperfeiçoamento daquela simples inferência" (DEWEY, 1952, p. 201). O controle intencional e deliberado a partir desse reconhecimento, exigirá a tomada de responsabilidade pelas conseqüências oriundas das ações a serem feitas pelo seu agente. Nesse sentido, o agente torna-se o que é e age de um determinado modo em razão de eventos passados cuja ação sobre ele demandara reações recíprocas, num processo aberto à continuidade no futuro.

Embora a educação, nas sociedades modernas, tornou-se uma necessária instituição de fomento à aprendizagem pelo ensino, constitui-se numa agenda promotora de experiências intencionalmente integradas devendo estar comprometida com a formação - sempre em curso - para a construção de um melhor agrupamento humano. Contudo, nos lembra Dewey da necessidade de aprofundarmos o conceito de experiência, uma vez que a associação desses dois fatores "educação e experiência" não é por si mesma includente, já que há experiências deseducativas e, neste caso, seriam termos opostos se considerarmos uma educação genuína como aquela que conduza o indivíduo ao crescimento em vista de novas experiências, num processo continuo. Quando a educação, contrariamente a este princípio, embota o individuo, tornando-o, por exemplo, insensível, 
domesticado, antissocial, ou afins, as experiências condutoras dessa formação (algumas delas podendo mesmo ser até muito agradáveis) resultaram antes no seu embrutecimento e na dificuldade para o engajamento em experiências futuras cada vez mais ricas para a construção de uma cadeia de interconexão de experiências cumulativamente organizadas. Um dos desafios apresentados por essas sugestões ao educador é o de constituir-se num profissional suficientemente hábil para saber selecionar as experiências construtoras de desenvolvimento humano e social, e promover o desbaratamento sistemático de contextos de experiências deseducativas.

Seria o contexto educativo o melhor lugar para as experiências de nível reflexivo? O autor nos mostra que "pensar" não é estar bem informado, simplesmente. Mas, “[...] considerar o influxo da ocorrência sobre o que pode suceder, mas ainda não sucedeu" (DEWEY, 1952, p. 202, grifos nossos) manifesta um pensar de qualidade superior associado à necessária capacidade inventiva e ao esforço reflexivo intenso. É ainda preocupar-se em apreender, prever o desfecho da ação tomada ou do acontecimento ocorrido que ainda não se concretizou totalmente. "Desejamos este ou aquele desfecho. Uma pessoa a quem seja totalmente indiferente o resultado não acompanha os acontecimentos nem pensa absolutamente a respeito" (DEWEY, 1952, p. 203). Desse modo, percebemos que a reflexão se ocupa de algo que ainda está por vir, logo, é incerta, gera dúvidas, apresenta-se de forma problemática. "Onde há reflexão há incerteza" (p. 203), nos ensina o autor, constituindo-se em esforços para superá-la pela investigação. Nesse sentido, o autor adverte:

Falamos algumas vezes como se a "pesquisa original" fosse prerrogativa de cientistas ou, pelo menos, de estudantes adiantados.

Filosofia e Educação [rfe] - volume 7, número 2 - Campinas, SP Junho-Setembro de 2015 - ISSN 1984-9605 - p. 47-74 
Mas todo o acto de pensar é investigação, é pesquisa e pesquisa pessoal, original, da pessoa que a faz, mesmo que todo o resto do mundo já conheça aquilo que ela procura descobrir (DEWEY, 1952, p. 204).

Pensar é ainda aventura e risco. A penetração no desconhecido é sempre carregada de incertezas diante da qual nos restam as hipóteses e as tentativas, a experimentação, "[...] seguir provisoriamente algum caminho" (DEWEY, 1952, p. 205), a exploração de possibilidades e de conjecturas, cujos passos tomados a partir dessas decisões mudam efetivamente, de algum modo, as condições físicas. Por isso, pensar se apresenta como um ato necessariamente "cuidadoso" e "deliberado" no estabelecimento de relações entre as ações e as suas consequências. Nesse contexto, a imaginação torna-se um recurso indispensável na lida com as incertezas e as dúvidas ditadas pela inexorável instabilidade do futuro.

\section{Elementos da experiência reflexiva}

$\mathrm{Na}$ sequência, apresento os fatores constitutivos de uma experiência de caráter reflexivo, a saber: 1) a perplexidade inevitável que emerge diante de uma situação incompleta, indeterminada e desconhecida; 2) a tentativa de previsão conjectural cuja interpretação da situação problemática busca apontar para algumas possibilidades solucionadoras futuras embasadas no desejo de realização ou expectativas; 3) a elaboração de cuidadoso exame em termos de: observação, inspeção, exploração, análise de todos os elementos que possam contribuir para a elucidação e enfrentamento do problema em pauta, tratado por um rigoroso estudo das condições reais e objetivas que estão em curso; 4) a elaboração de hipóteses feita em vista das consequências esperadas; 5) por fim, a elaboração de um plano de ação e 
provação efetiva das hipóteses, que é um trabalho constituído em vista do alcance da prova intencionada.

Desse modo, "Ao mesmo tempo em que o acto de pensar resulta em conhecimento, em última análise o valor do conhecimento subordina-se ao seu uso no acto de pensar" (DEWEY, 1952, p. 208), enquanto garantia para o futuro. $\mathrm{O}$ ato de pensar é, em última instância, “[...] o método da experiência inteligente em seu curso" (DEWEY, 1952, p. 210). A ação inicial presente na experiência comum ou situação empírica e natural é, portanto, verdadeiramente educativa e deve ser usada como ponto de partida buscada na experiência comum, para impulsionar o interesse e a aprendizagem, uma vez que estimula o pensamento em vista da incorporação de uma nova qualidade na experiência, a reflexão. Pois, “[...] o acto de fazer é de tal natureza que exige a reflexão ou a observação intencional das relações; daí, naturalmente, resulta a aprendizagem" (DEWEY, 1952, p. 212).

Assim, os elementos 3 e 4 fazem do ato de pensar uma efetiva "experiência" diferenciando do mero procedimento de "tentativa e erro" visto por Dewey como um grosseiro método de investigar, embora às vezes, usado pela dificuldade ao tentarmos apreender as consequências dos atos.

\section{Componentes “inseparáveis" da Experiência}

\begin{tabular}{|c|l|}
\hline \multicolumn{1}{|c|}{ Aspecto Ativo } & \multicolumn{1}{|c|}{ Aspecto Passivo } \\
\hline Fazer - experimentar - reagir. & Sofrer ou sentir as consequências da \\
& sua própria ação e as ações dos \\
& demais fatores sobre si, presentes na \\
& rede de interações. \\
\hline
\end{tabular}


Apenas didaticamente podemos apresentar tais componentes num esquema em que aparecem separadamente. Pois, na realidade temos interações, interconexões, ações-reações de diversos fatores presentes num enredamento contínuo, múltiplo, dinâmico e em permanente ritmo de mudança.

\section{Experiência qualitativa e educação}

Do mesmo modo que constatamos que na experiência humana há apenas rudimentos de elementos intelectuais que podem ser desenvolvidos, observamos que nem toda experiência possibilita ao homem a apreensão de sua qualidade estética, ou seja, nem todos apreendem a experiência em sua integralidade, logo, nem sempre isso acontece. Nem toda experiência vivida se revela em sua singularidade. Há frequentemente uma carência de feeling ao experienciar. Como exemplo disso podemos lembrar aquelas situações em que realizamos atividades ainda incipientes ou agimos de modo distraído, disperso ou letárgico. Ao concretizarmos uma ação, muitas vezes o fazemos de modo interrompido, descontínuo ou desconexo, não havendo o controle total da situação ou, ainda, não nos esforçamos por fazê-lo. Portanto, nesses casos, a experiência não se completou e não a apreendemos em sua singularidade, unicidade ou em seu momento consumatório. Nesse sentido, ela não poderá ser integrada ao repertório de experiências anteriores, como também, apresenta pouca ou nenhuma relação ao contexto em que ocorre, tampouco, podemos retirar dela qualquer possibilidade de futuro ou apreender as suas consequências. Tal experiência não se dá no 'processo contínuo', efetivamente. Não se trata, portanto, de nos satisfazermos em apenas termos chegado a uma cessação ou término de uma atividade, mas devemos tê-lo feito de modo a atingir sua consumação ou completude. $\mathrm{O}$ autor nos explica:

Filosofia e Educação [rfe] - volume 7, número 2 - Campinas, SP Junho-Setembro de 2015 - ISSN 1984-9605 - p. 47-74 
Nessas experiências, cada parte sucessiva flui livremente, sem interrupção e sem vazios não preenchidos, para o que vem a seguir. Ao mesmo tempo, não há sacrifício da identidade singular das partes [...] Em uma experiência, o fluxo vai de algo para algo. À medida que uma parte leva a outra e que uma parte dá continuidade ao que veio antes, cada uma ganha distinção em si.

Por causa da fusão contínua, não há buracos, junções mecânicas nem centros mortos quando temos uma experiência singular. Há pausas, lugares de repouso, mas eles pontuam e definem a qualidade do movimento (DEWEY, 2010, 111, itálico do autor).

Com efeito, quando há a qualidade estética na experiência, esse atributo impede a dispersão, o desmantelamento ou a desintegração da mesma, sob pena de, se assim for, não mais constituir-se em uma experiência genuína. Esta qualidade preza pela unidade e, ao mesmo tempo, pelo caráter próprio de cada parte que a constitui. Contudo, tal qualidade perpassa toda a experiência reconhecendo-a na sua integralidade e se desenvolve em sua base mesma, subjacente a ela, com os seus elementos intelectuais, afetivos e volitivos aí presentes. Desse modo, o fluxo de ideias, por exemplo, só é possível pela existência dessas experiências integrais, sem as quais não seria possível o pensar e nem mesmo a distinção de um pensamento cuidadoso e rigoroso de um outro desconexo. Por exemplo, a "conclusão" de um raciocínio representa a fase da experiência integral consumada, em evolução. Nas palavras de Dewey (2010, p. 113): “A 'conclusão' não é uma coisa distinta e independente; é a consumação de um movimento". E, podemos acrescentar: isso se dá graças à qualidade estética penetrante que está presente na experiência. Sem ela, o pensamento seria inconclusivo, como nos alerta o autor.

Filosofia e Educação [rfe] - volume 7, número 2 - Campinas, SP Junho-Setembro de 2015 - ISSN 1984-9605 - p. 47-74 
Em se tratando das implicações educacionais da teoria da experiência, inicialmente, devemos recuperar o que Dewey estabelece como prejuízos daqueles que não compreendem bem essas interações ricas e necessárias que ocorrem no âmbito da vida humana. Diz o filósofo:

A experiência é o resultado, o sinal e a recompensa da interação entre organismo e meio que, quando plenamente realizada, é uma transformação da interação em participação e comunicação. Visto que os órgãos sensoriais, com o aparelho motor que lhes está ligado, são meios dessa participação, toda e qualquer invalidação deles, seja de ordem prática ou teórica, é, ao mesmo tempo, efeito e causa de um estreitamento e um embotamento da experiência de vida. As oposições entre mente e corpo, alma e matéria, espírito e carne originam-se todas, fundamentalmente, no medo do que a vida pode trazer. São marcas de contração e retraimento. Portanto, o reconhecimento pleno da continuidade entre os órgãos, necessidades e impulsos básicos da criatura humana e seus antepassados animais não implica uma redução necessária do homem ao nível dos bichos. Ao contrário, possibilita o traçado de um projeto fundamental da experiência humana sobre o qual se erga a superestrutura da experiência maravilhosa e distintiva do homem. O que há de distintivo no homem lhe permite descer abaixo do nível dos animais. Também lhe possibilita elevar a alturas novas e sem precedentes a união do sentido e do impulso, do cérebro, olho e ouvido, que é exemplificada na vida animal, saturando-a com os significados conscientes derivados da comunicação e da expressão deliberada (DEWEY, 2010, p. 88-80, grifos nossos).

A educação, enquanto mecanismo de preservação da vida social, análoga aos esforços de renovação da vida natural, se define primariamente 
pela transmissão através da comunicação para a participação na experiência comum, a qual é importante para a preservação social. No entanto, a experiência só é educativa, na medida em que promove o desenvolvimento e o avanço aos patamares mais sofisticados do experienciar, podendo assim, reconstruir experiências anteriores e apontar para o futuro com maiores possibilidades de controle, de previsão, de garantia saudável ao crescimento humano.

Para que a teoria da experiência possa ser formulada de forma a dar conta de seus princípios e propósitos, é preciso, com efeito, que combatamos os impedimentos para a sua realização no seio da existência humana, a saber:

1) a vida compartimentalizada e hierarquizada, segundo categorias de superioridade e inferioridade dos seus compartimentos;

2) os dualismos, herdados desde a Antiguidade, entre mente-corpo, imaterialidade-materialidade, teoria-prática, etc. com as qualidades denotativas próprias a cada um dos elementos compartimentados postos numa hierarquia indicativa dos seus distintos lugares;

3) a sensação compreendida como estímulo mecânico e fator inferior na esfera da experiência humana constitui-se num outro impedimento ao permitir o ver sem ouvir; o ouvir sem, de fato, sentir; e assim por diante. Em nossas experiências, os sentidos muitas vezes não contribuem para a apreensão da unidade da experiência, sendo os mesmos tomados como condições superficiais e inferiores em relação ao discernimento, próprio da mente, do intelecto, do espírito;

4) a moral, marcadamente tendenciosa em relação à extremada valorização das bases intelectuais da experiência, equivocadamente torna os aspectos sensoriais apenas ligados às emoções, aos impulsos e apetites, a serem superados por uma mente e espírito não abandonados ao sabor da

Filosofia e Educação [rfe] - volume 7, número 2 - Campinas, SP Junho-Setembro de 2015 - ISSN 1984-9605 - p. 47-74 
carne. Há aqui uma identificação do sensório com o sensual e o lascivo. Nesse sentido, Dewey adverte: "Os sentidos são os órgãos pelos quais a criatura viva participa diretamente das ocorrências do mundo a seu redor [...] o assombro e o esplendor deste mundo se tornam reais para ela nas qualidades que ela vivencia" (DEWEY, 2010, p. 88). Logo, não há como dispensar o emocional e o afetivo na experiência humana.

5) a tendência em separar sensação, ação e pensamento enquanto fator provocador de pernicioso dualismo. Pois, se os sentidos, efetivamente presentes na vida orgânica dos indivíduos, incluem uma gama de conteúdos tais como: o sensorial, o sensacional (assombroso), o sensível, o sensato (o juízo) e o sentimental (as emoções), “[...] desde o choque físico e emocional cru até o sentido em si - ou seja, o significado [esclarecido] das coisas presentes na experiência imediata" (DEWEY, 2010, p. 88, acréscimos nossos), não podemos contrastar as sensações com a ação, porque a participação requer os órgãos motores dos sentidos, tampouco, podemos contrastá-las com o intelecto porque a mente é o meio pelo qual a participação é efetivada pelo juízo - tudo isso concorrendo para que os valores e os significados sejam interligados no contexto em que observamos integrados a criatura viva e o meio.

6) a desvalorização do corpo, que implica no fato de a atividade corpórea normalmente ter sido entendida enquanto algo divorciado da atividade perceptiva e intelectiva, admitindo-se o isolamento dos órgãos dos sentidos e dos músculos das atividades mentais e cognitivas e a separação do ato e seu objetivo produzindo o ato maquinal - o que não permite a percepção do "sentido" ambicionado na real experiência.

7) a separação do espírito e as coisas, cujo problema Dewey busca superar com sua sugestão de que haja uma experiência vivificante, através da qual se torne possível a apreensão das conexões das coisas detidas em

Filosofia e Educação [rfe] - volume 7, número 2 - Campinas, SP Junho-Setembro de 2015 - ISSN 1984-9605 - p. 47-74 
nossa atenção. É preciso conectar o "aspecto intelectual" da percepção e o discernimento das relações no contexto experiencial real em que encontramos a combinação do tentar uma ação (atividade; aspecto ativo da experiência) e o sofrer as consequências disso (aspecto passivo da experiência), cujo componente produtivo dessas ligações deve ser a "reflexão". Contudo, ressalta que "[...] toda a percepção e toda a ideia nada mais é do que o senso do alcance, do uso e da causa de alguma coisa" (DEWEY, 1952, p. 197). Como exemplo, cita o caso de uma cadeira que conhecemos pelo seu destino, conferido pelas conexões de suas características com as de outro objeto - sendo, portanto, distinta, digamos, de uma mesa. O julgamento se dá em base das nossas percepções.

No entanto, observamos, infelizmente, um desinteresse pelas coisas do mundo, da vida, um estreitamento da nossa percepção diante das relações que, contrariamente, é o que confere às coisas os seus verdadeiros significados. Quando assim não ocorre, contentamo-nos com pseudo-ideias, meias percepções, tornando semimorta a nossa atividade mental.

Com efeito, o domínio das consequências das ações que praticamos e que retornam a nós, é facilitado grandemente pela intelecção, pelo pensamento, pela reflexão, adicionados aos outros aspectos já apresentados - o que, no geral, viabiliza o aumento do valor da experiência e modifica a sua qualidade, em sua acomodação à esfera humana. Em outras palavras, sugerimos que nossa inserção consciente no mundo, quando a experiência se torna "reflexiva" e "significativa", implica no reconhecimento da indispensabilidade da percepção das conexões reais experimentadas, devendo ser esta devidamente acrescida da compreensão anteriormente mencionada - o que a difere da mera utilização do método de "tentativa e erro", por exemplo. 


\section{Palavras finais}

O próximo ano marcará um grande acontecimento filosófico-educacional a ser celebrado diante dos 100 anos de lançamento do notável livro de Dewey, Democracia e educação. É evidente que o sucesso editorial correspondeu ao pico de alta procura do livro, uma vez que o mesmo constituiu-se, especialmente, durante toda primeira a metade do século XX em influente leitura não só no exterior, mas também no Brasil, sendo revisitado com muito interesse ao longo dos anos subsequentes. Hoje, a presença deste título nas referências dos trabalhos de filosofia da educação ainda mantém-se, embora de maneira inconstante, mas servindo ainda como importante fundamentação teórica ou mesmo como objeto de estudo ao trazer as ideias do autor de forma mais sistematizada. Aliás, vimos observando uma retomada no interesse dos pesquisadores pelo autor e pelas ideias que comunga, nos dias atuais.

Com suas páginas vivamente folheadas pelos interessados na "renovação educacional" das primeiras décadas do século XX, Democracia e educação foi atentamente discutido por muitos intelectuais brasileiros, tendo sido ainda considerado à época um grandioso manual de filosofia da educação. Nele, o autor apresenta uma proposta educacional pautada na teoria ou filosofia da experiência com seus desdobramentos políticos, em contraposição ao modelo livresco, tradicional e autoritário até então imperante. A filosofia da educação como plano de ação se inscreve não somente como aquele saber detector dos problemas diante do que uma cuidadosa reflexão deve apurar, mas como um trabalho eminentemente investigativo que agrega ainda, e essencialmente, a descoberta por soluções dos conflitos e dúvidas que afligem a tranquilidade e conforto existencial humano. Estando o trabalho filosófico associado à educação opera uma 
ação de investigação e de formação em vista da construção de uma sociedade efetivamente democrática.

É evidente que a agudeza intelectual e ousadia de Dewey lhe renderam várias críticas, desde aqueles que acentuaram os seus traços conservadores ao sugerir, de certa forma, uma teoria de adaptação do homem a uma nova situação das sociedades progressivas e capitalistas, como também, surgiram outras acusações imputando a ele uma personalidade perigosa - mesmo socialista - e, por isso, ameaçadora ao status quo bem estabelecido. Outros evidenciaram os aspectos ingênuos de suas propostas tendo se tornado importante referência do movimento em favor do "otimismo pedagógico" que tão bem caracterizou, segundo essa crítica, aqueles que desvinculam a educação da sociedade, daí terem engendrado uma visão excessivamente otimista de educação enquanto fator fortemente mobilizador de mudanças. No tocante à filiação do autor ao pragmatismo, aliás, considerado como um dos seus formuladores clássicos junto a Peirce e a James, há também muitas incompreensões, cujas criticas mostram-se muito produtivas para os propósitos deste artigo ao tratar da experiência estética. Desse modo, o mal compreendido "instrumentalismo" interior à proposta do autor é, via de regra, confundido como uma manifestação marcadamente utilitarista, mas que, principalmente no contexto de sua filosofia da arte, se revela com um outro significado, a saber: "[...] o que quer que proporcione em alguma medida o enriquecimento da experiência imediata é, nessa medida, estético" (KAPLAN, 2010, p. 11), sendo portanto "instrumental" para o prosseguimento salutar do experienciar humano. Isso porque observamos uma enorme dificuldade para se conceber claramente o que a referida escola de filosofia diz respeito. Como exemplo disso, cito mais uma vez Abraham Kaplan que, na extensa Introdução que faz para o livro Arte como 
experiência (2010), procura analisar a produção do autor de maneira isenta, mostrando o que entende ser as suas fragilidades mas ostentando o seu valor como intelectual pragmatista, não vendo nele apenas uma mera filosofia da ação, mas que se trata, “[...] igualmente [de] uma filosofia do pensamento e do sentimento - o primeiro para nortear a ação, o segundo para identificar as consumações visadas pela ação" (KAPLAN, 2010, p. 11). Como sabemos, o que Dewey pretende é que, especialmente pela educação, consigamos nos munir de experiências de tal qualidade para que a isso corresponda uma ordem social de igual natureza. Pois, experiências fugazes, irrefletidas, passageiras, interrompidas, etc., não são educativas, nem formativas, uma vez que não permitem o processo de desenvolvimento humano cumulativo retrospectivo e prospectivo para o controle das consequências futuras em conexões contínuas, o que é requerido para a construção política de uma sociedade mais igualitária e mais justa.

Dewey nos ensina a pertinência aos nossos dias da perspectiva estética no âmbito da experiência humana, pois a arte recupera o assombro perdido no passado da humanidade embora dele tenha produzido a ciência. Contudo, a arte pode bem nos servir, considerando as certezas fortemente arraigadas no espírito do homem moderno, tomando-as como ponto de partida, para devolver a ele a sua capacidade do maravilhamento, do espanto. O exercício da prática artística e a incorporação da perspectiva estética na experiência humana podem ainda contribuir para o desembrutecimento humano, num combate à enrijecida absorção de tantas verdades e sede de certezas, próprias de uma cultura dualista que acabou por salientar excessivamente a força do intelecto e a capacidade produtiva da razão em detrimento das sensações, sentimentos e experiências, consideradas "fugazes". 
Ademais, retiramos da visão estética presente na teoria deweyana uma perspectiva necessária frente àquilo que caracteriza, segundo ele, a experiência existencial humana, naturalmente marcada pela fragilidade do mundo, restando ao homem valer-se especialmente dos recursos artísticos, dentre outros apresentados, para através deles estabilizar os seus sentimentos diante da instabilidade inerente à sua existência realizada na precariedade e nas incertezas. Buscar certezas, fim último, verdades definitivas, etc., constitui-se em pura ilusão. Nesse sentido, a aprendizagem decorrente da união da filosofia com a arte pode assim preparar melhor o homem para a busca de um mundo "ainda esperado", com o aporte da inteligência e do espírito investigativo humano.

Diante do exposto, não resta dúvida que estamos tratando de um autor complexo, de interesses amplos, de traços polêmicos haja vista as diversas interpretações sobre o seu perfil acima aludidas, o que requer uma leitura atenta de seus escritos. Contudo, o seu combate aos dualismos, cujas separações distanciaram, por exemplo, a natureza e a experiência, a teoria e a prática, o corpo e o espírito, a arte e a ciência, o racional e o empírico, o trabalho e o lazer, as artes-liberais e as artes-úteis, dentre outros, serve-nos até hoje como fonte de utilização dessas categorias de análise, em vista do acirramento que observamos entre escola e sociedade, intelectuais e trabalhadores, etc., que ainda atormentam nossas formulações explicativas. Se Dewey não é a solução para a problemática, certamente servirá como alternativa de análise muito produtiva.

No que diz respeito às suas sugestões filosófico-educacionais, as suas ideias não fugiram de um caminho já iniciado desde alguns séculos, embora isso feito de modo mais retraído e não tão contundente quando tratado por sua lavra. Já haviam surgido críticas agudas aos modelos educacionais focalizados no adulto, no intelecto, na persecução de valores absolutos e

Filosofia e Educação [rfe] - volume 7, número 2 - Campinas, SP Junho-Setembro de 2015 - ISSN 1984-9605 - p. 47-74 
finalidades deles decorrentes para a vida dos indivíduos (independentemente da época e local em que se vivia), dentre outros. Porém, Dewey foi beneficiado por uma gama de interesses em torno do homem e sua formação que possibilitou que usasse os recursos de várias ciências humanas, filosofia, arte e educação para enredar o fenômeno por ele focalizado. Sua visão englobante permitiu que vinculasse a ideia de educação, como formação humana de caráter socializante e formal escolar, à política, em sua expectativa de conquista da democracia. E isso tudo gerou inspiração para a formulação de uma nova teoria educacional, batizada posteriormente como progressivismo. Os princípios e sugestões progressivistas atingiram o ideário pedagógico da escola nova e permitiram o destaque na cena intelectual brasileira da figura emblemática inovadora de Anísio S. Teixeira, cuja vida dedicada à educação se deu sob o cultivo das ideias deweyanas associado a um talento profissional admirável.

Quanto às vinculações da filosofia da experiência com a referida teoria pedagógica, Dewey nem sempre ficou satisfeito, pelo contrário, buscou até mesmo justificar o que entendia como equívocos presentes nessa novidade. O livro disso resultante apareceu em 1938 com o título Experiência e educação no qual o autor mostra-se preocupado com a formulação de mais um "ismo" a partir de suas ideias. Para ele, isso tende a atenção mais ao oponente do que à "educação" em si mesma, esta que deveria ser o foco dos interesses principais, como também, o conjunto das preocupações ai engendrado propiciou, a seu ver, um desvio de ótica tentando mais atacar ao invés de atentar para as elaborações teóricas internas à proposta. Como resultado disso, o autor advertiu sobre o perigo de a nova proposta, ao defender a liberdade, sucumbir numa posição dogmática semelhante a que critica.

Filosofia e Educação [rfe] - volume 7, número 2 - Campinas, SP Junho-Setembro de 2015 - ISSN 1984-9605 - p. 47-74 
Sendo contrário aos dogmatismos, o autor ressalta que "[...] qualquer teoria e conjunto de práticas são dogmáticos quando não são baseados no exame crítico dos seus próprios princípios fundamentais" (DEWEY, 1963, p. 22, tradução nossa). Trata-se pois de uma proposta que defende a condução inteligente da educação tendo por base a experiência, nos termos aqui apresentados.

Daí o convite posto neste artigo para a busca pelo aprofundamento do conceito de experiência na educação, o qual, acrescentamos, estar presente mesmo nos jargões pedagógicos, além de ser subsídio teórico indispensável para entendermos as mais variadas propostas educativas nele centralizadas, especialmente, quando estas adotam posições críticas diversas em torno do conceito aqui em pauta. E, sem dúvida, Dewey é um autor que muito pode contribuir nessas investidas.

\section{Referências}

ALEXANDER, H. B. The Paul Carus Foundation. In: DEWEY, J. Experience and nature. $2^{\text {nd }} \mathrm{ed}$. Chicago \& London: Open Court Publishing Company, 1926, p. ix-xi.

DEWEY, J. Experience and nature. $2^{\text {nd }}$ ed. Chicago \& London: Open Court Publishing Company, 1926.

. Experience \& education. $1^{\text {st }}$ Collier Books ed. New York: Macmillan Publishing Company, 1963.

. Democracia e Educação. Trad. Godofredo Rangel e Anísio Teixeira. 2.ed.

São Paulo: Companhia Editora Nacional, 1952.

- Como Pensamos. Trad. e notas de Haydée de Camargo Campos. 3.ed. São

Paulo: Companhia Editora Nacional, 1959.

. Experiência e natureza. Trad. Murilo Otávio Rodrigues Paes Leme. 1.ed.

São Paulo: Abril S.A. Cultural e Industrial, 1974.

Filosofia e Educação [rfe] - volume 7, número 2 - Campinas, SP

Junho-Setembro de 2015 - ISSN 1984-9605 - p. 47-74 
- Arte como experiência. Trad. Vera Ribeiro. $1^{\mathrm{a}}$ ed. São Paulo: Martins Fontes, 2010.

KAPLAN, A. Introducão. In: DEWEY, J. Arte como experiência. Trad. Vera Ribeiro. 1.ed. São Paulo: Martins Fontes, 2010, p. 07-49.

SANTAYANA, G. Dewey's naturalistic metaphysics. In: SCHILPP, P. A. (ed.) The philosophy of John Dewey. $2^{\text {sd }}$ ed. New York: Tudor Publishing Company, 1951, p. 243-261.

TEIXEIRA, A. A pedagogia de Dewey - esboço da teoria de educação de John Dewey. IN: DEWEY, John. Vida e educação. Trad. Anísio S. Teixeira. $5^{\text {a }}$ ed. São Paulo: Edições Melhoramento: 1965, p. 13-41.

. Apresentação. In: DEWEY, J. Democracia e Educação. Trad. Godofredo Rangel e Anísio Teixeira. $2^{a}$ ed. São Paulo: Companhia Editora Nacional, 1952, p. 11-14. 